\title{
Positive acculturation conditions and well-being in a mine in the North-West Province
}

\author{
Authors: \\ Leon T.B. Jackson ${ }^{1}$ \\ Fons J.R. van de Vijver ${ }^{1,2}$ \\ Shanaz $\mathrm{Ali}^{1}$

\section{Affiliations:} \\ ${ }^{1}$ WorkWell Research Unit for \\ Economics and Management \\ Sciences, Potchefstroom \\ Business School, Economics \\ and Management Sciences \\ Faculty, North-West \\ University, Potchefstroom \\ Campus, South Africa \\ ${ }^{2}$ Department of Psychology, \\ Tilburg University, \\ Netherlands \\ Correspondence to: \\ Leon Jackson \\ Email: \\ Leon.Jackson@nwu.ac.za \\ Postal address: \\ Private Bag X6001, \\ Potchefstroom Campus, \\ North-West University, \\ Potchefstroom 2520, \\ South Africa \\ Dates: \\ Received: 16 June 2011 \\ Accepted: 29 Mar. 2012 \\ Published: 30 May 2012 \\ How to cite this article: \\ Jackson, L.T.B., Van de \\ Vijver, F.J.R., \& Ali, S. (2012). \\ Positive acculturation \\ conditions and well-being \\ in a mine in the North-West \\ Province. SA Journal of \\ Industrial Psychology/SA \\ Tydskrif vir Bedryfsielkunde, \\ 38(1), Art. \#997, 11 pages. \\ http://dx.doi.org/10.4102/ \\ sajip.v38i1.997
}

(C) 2012. The Authors. Licensee: AOSIS OpenJournals. This work is licensed under the Creative Commons Attribution License.
Orientation: Multiculturalism seemed to have become the dominant strategy for dealing with pluralism in the South African public sphere.

Research purpose: The authors addressed the relationship between conditions that are considered to be conducive to multiculturalism and the practices perceived to accomplish this, vis-à-vis multiculturalism and well-being, as measured by ill-health and subjective work success.

Motivation for the study: Although multiculturalism has been recommended as an effective way of dealing with diversity at societal and local levels, little is known about its effects in the workplace.

Research design, approach and method: Following a quantitative approach, the authors utilised a cross-sectional design with a convenience sample of 241 Black employees and White employees from a mine in North-West Province for the research. Exploratory factor analyses and Cronbach alpha coefficients were used to test scale validity and reliability. Multivariate Analysis of Variance (MANOVA) and effect sizes were used to determine the effect of race on the experiences of miners, and multigroup path analysis (AMOS) was used to investigate whether or not identical relations between multiculturalism, work success, and ill-health could be found for Black employees and White employees.

Main findings: Multiculturalism and mainstream tolerance coupled with ethnic integration demands at home and at work were associated with success at work but not with ill-health. Black employees experienced the workplace slightly more positively.

Practical/managerial implications: Multiculturalism and integration are related to subjective experiences of work success and, as such, should be supported in the workplace.

Contribution/value-add: Our findings suggest that multiculturalism is relatively well supported by both groups in the workplace. This positive finding should not be regarded as obvious because empirical research has suggested that the majority of members of the host culture do not always favour multiculturalism.

\section{Introduction}

The 1994 democratic elections have brought a new order to South Africa which encapsulates the protection of human rights. The fundamental goal of the African National Congress (ANC) remains to construct a non-racial, non-sexist, democratic society in South Africa. Increasingly, South African organisations are implementing employment equity and affirmative action programmes as organisations commit themselves to a process of redressing previous imbalances, because of discriminatory legislation, which has resulted in a very diverse workforce composition. These trends pave the way for multiculturalism as the dominant strategy for dealing with pluralism in South African society.

Multiculturalism is expected to have positive effects on ethnic groups and on intergroup relations. Although multiculturalism has been recommended as an effective intervention at societal and local levels, little is known about its effects in organisations (Richeson \& Nussbaum, 2004; Wolsko, Park, Judd \& Wittenbrink, 2000). It has been suggested that the impact of multiculturalism may differ between ethnic minority and majority groups. Bekker and Leildé (2004), in attempting to answer the question'Is multiculturalism a working policy in South Africa?' concluded that it appears that multiculturalism, both as a policy and as an outcome, has had a measure of success in the new South Africa. However, multiculturalism has been criticised on several grounds. Some have suggested that multiculturalism can lead to group distinctions, conflict and separatism (Brewer, 1997) whilst others have argued that multiculturalism endangers social unity and cohesion, and it also contradicts individualism and the ideal of meritocracy (Barry, 2001; Bissoondath, 1994; Schlesinger, 1992). Given the divergent views about the benefits of multiculturalism it seems 
relevant and important to investigate its relationship with well-being in a diverse workforce. Relating to this, acculturation studies focus on issues arising when groups or individuals from different cultures come into continuous first-hand contact with one another, with subsequent changes taking place in the original cultural patterns of either or both groups.

Our theoretical framework draws on a mediation model of acculturation (Arends-Tóth \& Van de Vijver, 2006). Predictors in the model, called multicultural conditions, refer to contextual conditions with a presumed influence on multicultural orientations, such as descriptive norms about the need to adopt and appreciate multiculturalism in a culturally diverse group. Mediating variables, called integration (orientations), refer to the way that individuals perceive their environment as either preferring to embrace multiculturalism (aimed at an integration of ethnic groups) or segregation (aimed at independent co-existence of ethnic groups); thus, our argument is that perceived practices and norms, vis-à-vis multiculturalism, will create perceived demands (to integrate or segregate) on the individual. These norms and practices (as antecedents to the research) and perceived demands (as mediating variables) will influence the outcomes of the process, such as well-being and work performance. The present study examines the multicultural model in a mine in the North-West Province and addresses differences in support for multiculturalism amongst Black employees and White employees.

The current study differs from conventional acculturation studies that include mainstream majority and immigrant minority groups. However, Jansen (2011) cautioned against the use of the term 'minority' because South Africans are building a common identity as citizens of a new country, where they no longer refer to each other by skin colour or demographic count, but by allegiance to higher values and commitments. He also warned that the term 'majority', in the new South Africa, should not be mistakenly interpreted as Black or African people, which is in line with our conceptualisation of the acculturation of ethnic groups in relation to the evolving new national identity. Heeding these warnings, we defined the context of adjustment as the new, multicultural South Africa. No ethnic group has a background that corresponds to this multicultural reality. So, we can safely assume that all groups are involved in an acculturation process, of dealing with this new reality, by either choosing to integrate with or segregate from other groups, most notably in the workplace. So, even though our study does not have the usually clear demarcation of mainstream and minority groups, we argue that acculturation theory provides a useful framework for studying the multicultural South African workplace.

\section{Antecedents: Mainstream multiculturalism conditions}

The impact of acculturation orientation of the host culture, dealing with the issue of how the dominant group prefers the immigrants to deal with the ethnic and mainstream culture, has been taken into account and is increasingly emphasised in studies relating to acculturation (Arends-Tóth \& Van de Vijver, 2000; Bourhis, Moise, Perreault \& Senecal, 1997). The Interactive Acculturation Model (Bourhis et al., 1997) takes the acculturation strategies (from the bidimensional model) of both the mainstream and minority culture into account. This model has been developed as a means to describe intergroup relations in a multicultural society, but can be readily extended to multiculturalism in the workplace. The conjunction of multicultural preferences, held by the various ethnicities in the work force, gives rise to various kinds of intergroup relations ranging from conflicting (e.g. all groups favour segregation and do not endorse integration) to consensual relations (e.g. groups favour multiculturalism). The nature of this relationship can be expected to have a similar impact on multiculturalism, as it has had on acculturation outcomes (Zagefka \& Brown, 2002). We examine multicultural practices and norms and mainstream tolerance as antecedent conditions:

- multicultural norms refer to descriptive rules about how diversity is dealt with in the organisation

- practices refer to behaviours, prevalent in the organisation, conducive to intercultural contact

- tolerance puts emphasis on non-discrimination during intercultural contact.

\section{Multiculturalism and mainstream tolerance}

Multiculturalism in the workplace refers to the co-existence and integration of the diverse cultures represented in the workforce. Multiculturalism is an ideology designed for dealing with cultural diversity, entailing the quality and positive evaluation of different groups within a society. Certain conditions must be met in order to establish and maintain a multicultural society (Berry \& Kalin, 1995). These conditions involve certain criteria:

- There should be contact between the ethnic groups.

- The society should be tolerant toward immigrant (minority) groups.

- All cultural groups should have positive attitudes toward each other and consider themselves attached to the larger society, without losing their own cultural background.

Empirical research, however, has suggested that the majority of host culture members do not always favour multiculturalism (Breugelmans \& Van de Vijver, 2004). Hofmeyr (2006) tried to establish the extent to which people, from different population groups, are being exposed to one another in their daily routines, and whether or not they want to increase contact with people from other groups. He found that more than half of their South African sample indicated that they never communicate informally with people from other ethnic groups on an average day, and that just less than a third of respondents indicated that they would like to increase their frequency of conversations with groups other than their own. Unlike the private domain where people have a choice about whom they communicate with, communicating with other group members in the workplace 
remains a reality, and given the rarity of such contacts in the personal sphere, one can only speculate about the impact forced contact exerts on well-being at work. Recent studies have indicated that multicultural practices and norms and mainstream tolerance in the workplace have been associated with lower levels of physical and psychological ill-health as well as increased subjective experiences of work success (Ait Ouarasse \& Van de Vijver, 2004; Molokoane, 2007; Swart, 2009). However, the following questions arise:

- Are these associations the same for both Black people and White people?

- Do these groups experience these acculturation conditions in the same fashion?

\section{Mediating variables: Perceived integration demands}

In this article, ethnic integration demands refer to pressure, from co-ethnics at home and at work, to recognise diversity and to adopt the multicultural (Rainbow) identity. Few studies have addressed the consequences of multicultural attitudes. However, various studies have addressed the closely related concept of acculturation orientations that deal with the question of how immigrants want to deal with their culture of origin and with the culture of the country of settlement. Berry, Phinney, Sam and Vedder (2006), in a large international study of immigrant youth in 13 countries, examined how these immigrant youth live and perform within and between two cultures. They concluded from their findings that the integration profile was the most common method of dealing with two cultures. Respondents with this profile reported relatively high scores on involvement in both their ethnic and national cultures, and on both ethnic and national identities. They also had peer contacts with both their own group and the national group and appeared to be comfortable in both their ethnic and national contexts. Immigrant youth, in the integration profile, obtained psychological and socio-cultural adaptation scores that were above the grand mean. These results supported their expectation that an ethnic orientation would contribute positively to psychological adaptation, and a national orientation would positively influence sociocultural adaptation. Positive relations between integration demands, and subjective experiences of success at work as well as lower levels of ill-health, were also confirmed in recent studies (Ait Ouarasse, 2004; Molokoane, 2007; Swart, 2008). There is overwhelming evidence for the positive effects of integration compared to the other ethnic acculturation strategies on adjustment and adaptation, yet, Neto, Barros and Schmitz (2005), when comparing the effects of integration and separation on 118 Portuguese immigrants in Germany, found no differences in acculturative stress, self-esteem, or satisfaction with life. The authors argued that these findings can probably be explained by the fact that the majority of Portuguese immigrants have been living in Germany for a long time and that their (objective) acculturation stress is low because these migrants have already developed efficient acculturation strategies. Research has often shown that integration is the strategy most favoured by minority members (e.g. Pham \& Harris, 2001; Zagefka \& Brown, 2002).
However, they may shift to separation if the mainstream culture reacts negatively to their integration (Ward, 2001). A host society that does not permit cultural diversity is not likely to favour integration but tends to favour minority assimilation rather than integration (Ait Ouarasse, 2004).

Similarly, Jasinskaja-Lahti, Liebkind, Horenczyk and Schmitz (2003) found that immigrants who preferred the separation option reported fewer stress symptoms than those who preferred the assimilation or integration options. Born $(1970)$ and Berry $(1970,1980)$ presumed that the modes of acculturation are responsive options for coping with acculturative stress, such that that the following is likely:

- high levels of stress cause people to choose acculturative withdrawal (separation or marginalisation with resulting lower or fewer stress symptoms after a period of time)

- low levels of stress cause people to choose acculturative engagement (assimilation or integration).

Sam (2000) found that immigrant adolescents in Norway who preferred integration suffered increased acculturative stress. People who preferred to separate themselves were less exposed to unwelcome, hostile attitudes and behaviour from the 'others'. It could be speculated that separation strategies will only be successful in contexts where this option is viable and the immigrant can withdraw into an ethnic pocket without having to frequently interact with the mainstream culture. We can only speculate about the association between pressure from co-ethnic members to integrate with multiculturalism and mainstream tolerance on the one hand, and psychological and sociocultural adaptation on the other hand in a diverse work context in South Africa.

\section{Outcomes: Well-being and work success}

We draw (again) on the acculturation literature to distinguish between two types of outcomes (Ward, Bochner\& Furnham, 2001). Psychological outcomes are mainly studied in the stress and coping tradition and concern mental health and general satisfaction with work: Does the employee feel well in the workplace? Sociocultural outcomes, on the other hand, are studied in the culture learning tradition, and refer to successful participation in the work force: Does the employee do well in the workplace? Psychological and sociocultural adaptation are positively related (Berry, 2003; Ward et al., 2001; Ward \& Kennedy, 1999) and the strength of the association is related to the cultural distance and the degree of integration of cross-cultural travellers in the social milieu. Thus, the larger the cultural distance, the weaker the association between psychological and sociocultural adaptation; the more the orientation toward the host society (assimilation or integration), the stronger the relation (Ward \& Rama-Deuba, 1999). Psychological and sociocultural outcomes may have different antecedents (Ward et al., 2001).

\section{The present study}

It seems reasonable to expect multiculturalism to be present in the mining industry, following the post-apartheid constitution of 1997 and the ensuing introduction of affirmative action 
and Broad Based Black Economic Empowerment (BBBEE) in the labour sector. The reality according to the Commission for Employment Equity (CEE) Annual Report 2009/2010 (Department of Labour, 2010), however, indicates the slow pace of transformation in the industry. The gender and racial distribution of the workforce in the sector is hardly reflective of the workforce diversification that the department had envisaged. The CEE report observes that after 10 years of affirmative action having been adopted as policy, progress on diversification of management, core-skilled management, and core-skilled workers remains minimal (Khuzwayo, 2010). Given this state of affairs, the following questions arise:

- Do mine workers, in a mine in the North-West Province, actually experience multiculturalism and mainstream tolerance and well-being?

- Do members of the Black and White ethnic group in South Africa, employed at this gold mine, promote the idea of integration and active participation in the workplace?

- Does the same multicultural mediation model (of antecedent, mediating, and outcome variables) apply to Black groups and the White group?

\section{Research design Research approach}

This research began with a quantitative approach, followed by a cross-sectional survey design whereby a sample was drawn from a population at one point in time, and this sample was used to obtain the research objectives. Cross-sectional designs are appropriate where groups of participants, at various stages of development, are studied simultaneously, whereas the survey technique of data collection gathers information from the target population by means of questionnaires (Burns \& Grove, 1993). This design is used to assess interrelationships amongst variables within the population.

\section{Research method}

\section{Sampling and research participants}

The participants of this study were a convenience sample of gold miners in the North-West Province. A total of 500 miners were approached. A response rate of 59\% was achieved, of which 288 responses (98\%) could be utilised. However, some of the Indian respondents were deleted from the final multigroup analysis because of their small sample size. Black and Coloured miners were combined as a single Black group to create a Black group and a White group for further analysis. The sample $(N=241: 83.7 \%$ of the initial usable sample) consisted of 208 males (86.3\%) and 33 females (13.7\%), 170 Black miners (70.5\%) and 71 White miners (29.5\%) with an average age of 31.65 years and 8.77 years of experience. Coloured miners comprised only $2.4 \%$ of the sample. Despite their cultural differences, given the history of the country as well as the low representation of Coloured miners, we decided to combine Black miners and Coloured miners for multigroup analyses. As an aside, it may be noted that our definition is in line with the Employment Equity
Act in which all previously disadvantaged groups are called Black: 'Black people' is a generic term which means Africans, Coloureds and Indians in the South African Employment Equity Act 55 of 1998. Within the context of the present study, both groups share a history as the victims of institutionalised racism and oppression, and they share the same position in the commonly perceived divide of 'black' and 'white' in South Africa (Makhalemele, 2005):

The original separation strategy of the National Party after the 1948 election only distinguished between black or 'non-white' and white. Apartheid created race as a mechanism for violence. Race, in and of itself, was the social and psychological reality through which repression and violence functioned. Racism was institutionalised, legalised and internalised." South Africans saw the world in 'black' and 'white' terms and violence was commonly used to maintain the status quo. (n.p.)

\section{Measuring instruments}

Some instruments, with well-established psychometric properties used in other cultural contexts, were adapted (Ait Ouarasse \& Van de Vijver, 2004). Adaptations involved replacing the original words 'Dutch' and 'Moroccan' with 'South African' and 'own ethnic group', respectively. All acculturation scales follow a 5-point Likert format ranging from 1 (strongly agree) to 5 (strongly disagree) and, where needed, item scores were reversed before the analyses. Adaptation of mainstream domain instruments:

- multicultural norms

- tolerance by the mainstream

- multicultural practices.

Multicultural norms (developed for the study by the researchers involved): This is a 6-item measure of the participants' attitudes to multiculturalism and the prevalence of multicultural values within an organisation. The scale contains items like 'I think that most of my co-workers think that the idea of a 'Rainbow Nation' with a core set of values, such as equality for all South Africans, does not work in our organisation' (reverse scored). An exploratory factor analysis suggested the unifactorial nature of the scale, and the same was found for all other scales in the study $(\alpha=0.65)$.

Tolerance by the mainstream (adaptation of Ait Ouarasse and Van de Vijver, 2004): This is an 8-item measure of the extent to which participants think that mainstream members take an open stance toward the ethnic minority in the South African workplace. Tolerance is the desire on the part of the mainstream to see the minority members actively involved in public life without necessarily dropping their original culture. The scale contains items like 'I think that most of my co-workers from other cultures are most welcoming people' $(\alpha=0.76)$.

Multicultural practices: This new instrument is a 7-item measure of the participants' actual multicultural behaviour and the prevalence of multicultural practices within an organisation. The scale contains items like 'My co-workers generally show respect for people from other cultures in our organisation' $(\alpha=0.77)$. 
Adaptation of ethnocultural domain instruments:

- Perceived ethnic integrationist demands (General)

- Perceived ethnic integrationist demands (Workplace)

Perceived Ethnic Integrationist Demands - General (adaptation of Ait Ouarasse \& Van de Vijver, 2004): This is a 6-item measure of the extent to which participants think that members of their ethnicity allow them to establish contact with the South Africans and participate in public life. The scale contains items like 'Most members of my cultural group want me to deal with people from different cultural groups' $(\alpha=0.75)$.

Perceived Ethnic Integrationist Demands - Workplace (adaptation of Ait Ouarasse and Van de Vijver, 2004): This is a 6-item measure of the extent to which participants think members of their own group allow them to establish contact with members of other ethnic groups members at work. The scale contains items like 'My group members are positive about diverse work teams' $(\alpha=0.71)$.

Psychological and socio-cultural acculturation outcomes:

- well-being

- work success.

Well-being: This is an adapted version of the 18 physical health symptoms of the PSI of Spector and Jex (1998), complemented with a list of 9 common psychological complaints based on a slightly modified version of the World Health Organization Cross-National Survey of Psychological and Somatic Symptoms (1988). This scale employs a frequency format that ranges from 1 (never) to 5 (every day). The self-report measure asks respondents to indicate whether or not, in the past three months, they had suffered any of the mentioned symptoms. Some examples of symptoms included in the scale are headaches, backache, fatigue, eyestrain and trouble sleeping, concentrating and constant anxiety or panic attacks ( $\alpha=0.94$ and 0.89 for physical and psychological illhealth, respectively).

Work success (Ait Ouarasse \& Van de Vijver, 2004): This is a 14-item measure of participants' success at work. All of the items are positively phrased. It contains items pertaining to task completion, punctuality, status, and recognition at work, relationships with supervisors, and relationships with fellow workers. The scale contains items like 'I am always on time for my work', 'I do my work exactly as instructed by my supervisor' and 'I have a good reputation among my co-workers' ( $\alpha=0.85)$.

A Biographical questionnaire is included in order to enable description of the population. It includes basic biographical questions like age, sex, race, and experience.

\section{Research procedure}

The research project was initiated after discussions with the Human Resource Department of a major gold mine in the North-West Province of South Africa, and permission was obtained from the mine's management. Various information sessions were held on site and pamphlets were distributed to inform employees about the aim of the project and to encourage them to attend sessions on site where participants would complete questionnaires. Managers were also encouraged to allow employees to attend the sessions for completion of the questionnaires whilst the anonymous and voluntary nature of the project was constantly emphasised during the information sessions. Five sessions were scheduled for questionnaire completion with two facilitators being present to clarify issues raised by the participants.

\section{Statistical analysis}

The statistical analysis was carried out using the SPSSprogramme (SPSS Inc, 2010) and the AMOS 18 programme (Arbuckle, 2010). Descriptive statistics were used to explore the data whilst Multivariate Analysis of Variance (MANOVA) was carried out with race (two levels: Black and White) as independent variable and the mean scores of the scales as dependent variables. A MANOVA tests whether or not mean differences amongst groups of people, on a combination of dependent variables, are likely to have occurred by chance when, as was the case in our data as documented below, the dependent variables are correlated (Tabachnick \& Fidell, 2007). Effect sizes (Cohen, 1988) were included, in addition to statistical significance, to determine the significance of relationships. Effect sizes indicate whether or not obtained results are practically important (whereas statistical significance may often show results which are of little practical relevance).

Exploratory factor analyses and Cronbach alpha coefficients were used to determine the unidimensionality, homogeneity, and internal consistency of the measuring instruments (Clark \& Watson, 1995). Cronbach's alpha coefficient contains important information regarding the proportion of variance of the items of a scale, in terms of the total variance explained by that particular scale. Pearson product-moment correlation coefficients are used to specify the relationship between the variables. Effect sizes (Steyn, 1999) are used to decide on the practical significance of the findings. A cut-off point of 0.30 (medium effect; Cohen, 1988) was set for the practical significance of correlation coefficients. In terms of statistical significance, the value was set at a $95 \%$ confidence interval level $(p \leq 0.05)$.

The mediating role of the demands of ethnic integration was investigated in the relations between positive antecedent mainstream conditions and well-being. To investigate these, structural equation modelling (multigroup analysis) was performed using AMOS 18 (Arbuckle, 2010).

\section{Results}

The results consist of three parts, namely:

- factor analysis and relationships between positive antecedents and intervening variables and well-being for Black miners and White miners

- testing of the mediating role of integration demands in the relations between antecedents of multiculturalism and well-being 
- similarities and differences amongst Black miners and White miners in antecedents and intervening variables and well-being.

\section{Exploratory factor analyses and associations between antecedent conditions, intervening variables and well-being for Black miners and White miners}

The results obtained from exploratory analyses and inspections of the scree plots indicated that all scales used were unifactorial, explaining $32.6 \%$ of the variance in multicultural norms, $46.6 \%$ in mainstream tolerance, $43.6 \%$ in multicultural practices, $44.8 \%$ in ethnic integration demands at home, $41.3 \%$ in ethnic integration demands at work, $47.8 \%$ in physical ill-health and $52.6 \%$ in psychological ill-health and $35.5 \%$ in perceived work success. The correlation matrix depicting construct associations for the Black (upper section of the matrix) and White (lower section of the matrix) group are presented in Table 1.

\section{A model of the mediating role of ethnic integration demands in the relations between positive acculturation antecedent mainstream conditions and well-being}

To investigate the mediating role of ethnic integration demands in the relations between positive antecedent mainstream conditions and well-being, structural equation modelling (multigroup analysis) was performed using AMOS 18 (Arbuckle 2010). There are three positive acculturation mainstream antecedent conditions in this model, namely multicultural norms, mainstream tolerance and multicultural practices. There is a single latent variable (well-being at work) that is measured using three indicators, namely physical and psychological ill-health (psychological adjustment) and work success (sociocultural adjustment). Finally, there is an ethnic latent variable (ethnic integration) that is measured using two indicators, namely ethnic integration demands at home and at work. The tested model postulates that acculturation mainstream conditions influence well-being at work through ethnic integration. The similarities and differences between the Black and White race groups were explored by testing the fit of a hierarchy of models with increasing constraints on the number of invariant parameters (see Table 2).

Inspection of Table 2 revealed that the structural residuals model (see Figure 1) was the most restrictive model with an acceptable fit: $\chi^{2}(48, N=241)=71.61, p<0.05 ; \chi^{2} / d f=1.49$ (recommended, $\leq 3.00$ ). Other indices confirmed the good fit of the model: The adjusted goodness of fit index (AGFI) was 0.90 (recommended, $\geq 0.90$ ), the Tucker Lewis index (TLI) was 0.95 (recommended, $\geq 0.90$ ), the comparative fit index (CFI) was 0.95 (recommended, $\geq 0.90$ ), and the root mean square error of approximation (RMSEA) was 0.05 (recommended, $\leq .05$ ). The results of the structural residuals model is presented in Figure 1. In this model the regression coefficients of the antecedent mainstream acculturation conditions and factor loadings on well-being at work, through ethnic integration and the latent variable as a mediating variable, were assumed to be invariant across both Black and White race groups. As can be seen in Figure 1, an increase in positive mainstream multicultural norms, mainstream tolerance and multicultural practices are associated with increased ethnic integration demands at home and at work.

Stronger associations were observed between mainstream tolerance and integration compared to the associations between integration and multicultural practices and norms. Figure 1 also indicates an insignificant path from integration to well-being, whereas a significant path was observed from

TABLE 1: Correlation matrix with all variables for Black miners (above diagonal) and White (below diagonal) miners.

\begin{tabular}{|c|c|c|c|c|c|c|c|c|}
\hline \multirow[t]{2}{*}{ Variables } & \multicolumn{8}{|c|}{ Variables } \\
\hline & 1 & 2 & 3 & 4 & 5 & 6 & 7 & 8 \\
\hline 1. Multicultural norms & - & $0.18^{*}$ & $0.20^{* *}$ & $0.32^{* *}$ & 0.08 & 0.11 & $0.19^{*}$ & 0.10 \\
\hline 2. Mainstream tolerance & 0.02 & - & $0.51^{* *}$ & $0.37^{* *}$ & $0.38^{* *}$ & -0.02 & -0.02 & $0.31^{* *}$ \\
\hline 3. Multicultural practices & 0.08 & $0.48^{* *}$ & - & $0.38^{* *}$ & $0.24^{* *}$ & -0.12 & -0.02 & $0.31^{* *}$ \\
\hline 4. Ethnic integration demands at home & $0.27^{*}$ & $0.48^{* *}$ & $0.33^{* *}$ & - & $0.49^{* *}$ & -0.01 & 0.03 & $0.36^{* *}$ \\
\hline 5. Ethnic integration demands at work & 0.03 & $0.52^{* *}$ & $0.37^{* *}$ & $0.57^{* *}$ & - & -0.09 & -0.06 & $0.37^{* *}$ \\
\hline 6. Physical ill-health & 0.14 & 0.14 & 0.02 & 0.19 & 0.03 & - & $078^{* *}$ & -0.15 \\
\hline 7. Psychological ill-health & 0.21 & 0.05 & -0.02 & 0.13 & -0.07 & $0.86^{* *}$ & - & $-0.20^{* *}$ \\
\hline 8. Work success & 0.08 & 0.11 & $0.44^{* *}$ & $0.27^{*}$ & $0.37^{* *}$ & -0.17 & -.023 & - \\
\hline
\end{tabular}

$*, p<.05 ;{ }^{* *}, p<.01$

TABLE 2: Results of the multigroup structural equation model analysis.

\begin{tabular}{|c|c|c|c|c|c|c|c|}
\hline Model & $\chi^{2} / d f$ & AGFI & TLI & CFI & RMSEA & $\Delta \chi^{2}$ & $\Delta d f$ \\
\hline Unconstrained & $1.91^{*}$ & 0.87 & 0.91 & 0.95 & 0.06 & - & - \\
\hline Measurement weights & $1.75^{*}$ & 0.88 & 0.92 & 0.95 & 0.06 & 1.96 & 4 \\
\hline Structural weights & $1.64^{* *}$ & 0.89 & 0.93 & 0.95 & 0.05 & 2.77 & 4 \\
\hline Structural covariances & $1.55^{* *}$ & 0.90 & 0.94 & 0.95 & 0.05 & 5.65 & 6 \\
\hline Structural residuals & $1.49^{* *}$ & 0.90 & 0.95 & 0.96 & 0.05 & 0.22 & 2 \\
\hline Measurement residuals & $1.60^{*}$ & 0.90 & 0.94 & 0.94 & 0.05 & $11.39^{*}$ & 4 \\
\hline
\end{tabular}

$\chi^{2} / d f$, relative Chi square; AGFI, Adjusted Goodness of Fit Index; TLI, Tucker Lewis Index; CFI, Comparative Fit Index; RMSEA, Root Mean Square Error of Approximation; $\Delta \chi^{2}$, changes in Chi square; $\chi^{2} / d f$, relative Chi square; AGFI, Adjusted
$\Delta d f$, changes in degrees of freedom.

$\Delta d f$, changes in degrees
$*, p<.05 ;{ }^{*}, p<.01$. 


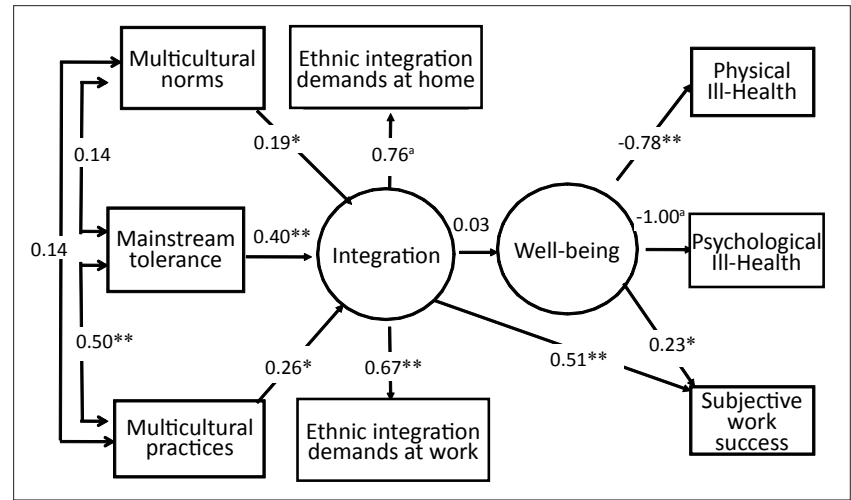

Source: Authors' own data

, regression weight was fixed (at a value of -1 ) to set the length of the latent factor (in line with common practice to fix one factor loading to define the metric of the latent variable). $*, p<.05 ; * *, p<.01$

FIGURE 1: The results of the multigroup structural equation model analysis.

integration to (only) work success. This finding suggests that the perceived multicultural climate, practices and demands are unrelated to well-being in this sample, but are related to work success. Employees who are more supportive of multiculturalism showed more (self-reported) work success.

\section{Mediating effects of integration demands}

The hypothesised model is a mediation model in which positive antecedent conditions influence ethnic integration demands, which in turn impact on well-being of mine workers. We made a closer examination of their direct and indirect effects to evaluate their relative quantities and to establish whether or not indirect effects were significant. There is quite some literature on the testing of mediation effects that describes alternatives to the commonly employed Baron and Kenny (1996) procedure (Holmbeck, 1997; Hoyle \& Kenny, 1999; Judd \& Kenny, 1981; Kline, 1998; Preacher \& Hayes, 2004). It has been found that the method proposed by Baron and Kenny (1986) can have a low statistical power, and that joint significance tests involving the product of coefficients showed greater statistical power than other procedures, including the Baron and Kenny approach (MacKinnon, Lockwood, Hoffman, West\& Sheets, 2002). Therefore, we kept within the structural equation framework to compute the significance of indirect effects by using the bootstrap procedure, as implemented in the AMOS program. The results of the analysis can be found in Table 3 .

Closer inspection of Table 3 indicated that, in agreement with observations from Figure 1, total and indirect effects where observed of subjective experience on work success but not on physical and psychological ill-health. In addition, the insignificance of all direct affects suggests that the link with subjective work success is fully mediated by integration demands. Positive antecedent variables have, therefore, an indirect and significant influence on subjective experience of work success. It can be concluded that integration demands fully mediate the path from mainstream positive conditions to sociocultural adjustment and that multiculturalism (integration) matters for the experience of subjective work success.

\section{Comparisons of Black groups and White groups}

Black and White group differences were examined, in the experience of mainstream antecedent conditions, ethnic integration demands at home and at work and also wellbeing. In order to examine these, a multivariate analysis of variance (MANOVA) was carried out with race (two levels: Black and White) as an independent variable and the mean scores of the scales as dependent variables. As can be confirmed in Table 1, various dependent variables showed significant correlations, therefore, we decided to conduct a MANOVA. The mean scores of the scales per race group are presented in Table 4.

TABLE 3: Mediation effects of integration eemands in the workplace (standardised effects).

\begin{tabular}{|c|c|c|c|c|c|c|c|c|c|}
\hline \multirow[t]{2}{*}{ Predictor } & \multicolumn{3}{|c|}{ Physical ill-health } & \multicolumn{3}{|c|}{ Psychological ill-health } & \multicolumn{3}{|c|}{ Work success } \\
\hline & Direct & Indirect & Total & Direct & Indirect & Total & Direct & Indirect & Total \\
\hline Multicultural practises & 0.00 & 0.01 & 0.01 & 0.00 & 0.01 & 0.01 & 0.00 & $0.13^{* *}$ & $0.13 * *$ \\
\hline Mainstream tolerance & 0.00 & 0.01 & 0.01 & 0.00 & 0.01 & 0.01 & 0.00 & $0.20 * *$ & $0.20 * *$ \\
\hline Multicultural norms & 0.00 & 0.00 & 0.00 & 0.00 & 0.01 & 0.01 & 0.00 & $0.09 *$ & $0.09 *$ \\
\hline Integration demands & 0.00 & 0.02 & 0.02 & 0.00 & 0.03 & 0.03 & 0.51 & -0.01 & 0.50 \\
\hline
\end{tabular}

$*, p<.05 ; * *, p<.01$

TABLE 4: Mean scores (SD) per scale for the sample, Black group and White group.

\begin{tabular}{|c|c|c|c|c|c|c|}
\hline \multirow[t]{2}{*}{ Variables } & \multicolumn{2}{|c|}{ M } & \multicolumn{2}{|c|}{ SD } & \multirow[t]{2}{*}{ Cohen's $d$} & \multirow[t]{2}{*}{ Item mean range for scale } \\
\hline & Black & White & Black & White & & \\
\hline 1. Multicultural norms & 3.31 & 3.06 & 0.77 & 0.64 & $0.34 *$ & $2.90-3.70$ \\
\hline 2. Mainstream tolerance & 3.51 & 3.36 & 0.69 & 0.65 & 0.22 & $3.24-3.57$ \\
\hline 3. Multicultural practices & 3.69 & 3.70 & 0.72 & 0.63 & -0.01 & $3.43-3.85$ \\
\hline 4. Ethnic integration demands at home & 3.73 & 3.58 & 0.64 & 0.71 & 0.23 & $3.36-3.81$ \\
\hline 5. Ethnic integration demands at work & 3.65 & 3.55 & 0.57 & 0.63 & 0.17 & $3.36-3.78$ \\
\hline 6. Physical ill-health & 2.00 & 1.93 & 0.83 & 0.74 & 0.09 & $1.53-2.69$ \\
\hline 7. Psychological ill-health & 1.95 & 1.92 & 0.85 & 0.86 & 0.04 & $1.74-2.23$ \\
\hline 8. Work success & 3.86 & 3.85 & 0.56 & 0.59 & 0.02 & $3.37-4.01$ \\
\hline
\end{tabular}

$\mathrm{M}$, mean; SD, standard deviation.

$*, p<.05$ (small effect size). 
The multivariate effect of race was not significant (Wilks's lambda $=0.957, F(8,232)=1.297, p=0.25)$. The only significant univariate effect was found for multicultural norms. Black miners experienced higher multicultural norms at work compared to White miners. The last column presents Cohen's $d$ values, which gauge the size of the race differences. Only negligible differences to small effect sizes were observed. Thus, even though Black miners tend to show somewhat higher scores on the antecedent and mediating variables, the effect sizes are small. Moreover, given that all score means are well above the scale midpoints, our data suggest that the work force of our study is well aware of the multicultural aspects of the workplace, and seems to acknowledge that their environment wants them to adapt to this diversity. Although the impact of social desirability cannot be ruled out, our data suggest that multiculturalism is relatively well supported by both groups, and that the attitudes amongst employees are conducive for establishing and maintaining good intergroup relations in the workplace. All dimension scores are high, and well above the midpoint of the scale, which suggest that the multicultural conditions experienced by these mine employees are favourable. Black miners seem to experience a slightly more favourable multicultural environment, although the differences are very small and are only significant for multicultural norms.

Although scale scores were above the scale midpoint, analysis of group differences, on item-level, suggested an average item mean for the two groups on multicultural norms that ranged between 2.90 and 3.70. Furthermore, these differences, with a small effect size, only exist in the experience of item 'I think that most of my co-workers do not recognise that we are a workforce that consists of groups from different cultural backgrounds' (reversed scored) $(d=0.46)$, with Black miners scoring higher than White miners, and that the smallest difference $(d=0.03)$, between Black miners and White miners, was reported for the item 'I think that most of my co-workers believe that a workgroup with members from a variety of cultural groups can better tackle new problems of our organisation'. The average item mean for the two groups on multicultural practices ranged between 3.43 and 3.85, with the smallest difference on item-level experienced for the item 'I think that most of my co-workers accept the fact that we have different cultural practices' $(d=0.02)$ and the largest differences, yet still with a small effect size, was experienced for the item 'My co-workers generally show respect for other cultures in our organisation', with White miners experiencing the items more positively than Black miners. Furthermore, we also observed that the average item mean for the two groups on mainstream tolerance ranged between 3.24 and 3.57. The largest difference (with a small effect size) between the two groups were seen in the scores of the item 'I think that most of my co-workers from other cultures do their best to understand and help people from other cultures' $(d=0.32)$ and the smallest difference was for the item 'I think that most of my co-workers believe that cultural minorities should be helped to preserve their cultural heritage' $(d=-0.08)$, with Black miners scoring higher than White miners.
Results also indicated that the average item mean for ethnic integration demands in general ranged between 3.36 and 3.81, that the largest difference, with a medium effect size, was observed in the item 'Most members of my cultural group want me to be a good member of my own cultural group and of the larger South African society' $(d=0.50)$, with Black miners scoring higher than White miners. The smallest difference $(d=0.03)$ was for the item 'Most members of my cultural group like to see its members playing a positive role in society'. Lastly, our results from the item-level analyses also indicated that the average item means for ethnic integration demands at work ranged between 3.36 and 3.78 with the largest difference being found between the groups for the item 'Most members of my cultural group want me to show my cultural values and respect those of others' ( $d=0.25$, small effect size), with Black miners scoring higher than White miners, and the smallest difference was for the item 'My cultural group members are positive about diverse work teams' $(d=0.03)$. It can be concluded that race differences were fairly small on average and that, if present, Black miners tended to have higher scores than White miners. Furthermore, there is no simple patterning of which items show large (or small) differences. Furthermore, it is a striking finding that almost all items showed mean scores well above the scale midpoint. This observation could not be simply dismissed as acquiescence, as we also included some reverse scored items. We cannot exclude the role of social desirability; yet, the multicultural practices scale correctly, which are mostly related to associated behaviours and may, therefore, be least susceptible to the influence of social norms. This also has item means well above the scale midpoint. Furthermore, we know, from cross-cultural studies, that countries and the ethnic groups within them often differ considerably in social desirability (van Hemert, Van de Vijver, Poortinga \& Georgas, 2002). Thus, if anything, social desirability would have increased the size of the cross-cultural differences.

\section{Discussion}

The aim of the study was to determine the relationship between mainstream antecedent conditions, ethnic intervening variables, and well-being at work for both Black miners and White miners. Antecedent mainstream conditions were positively related to ethnic integration demands and work success and unrelated to ill-health. This implies that a work environment characterised by increased multicultural norms and practices and tolerant mainstreams, is more likely to contribute to members of a particular ethnicity encouraging each other to participate in mainstream multiculturalism, as well as experience higher levels of subjective work success (Molokoane, 2007; Swart, 2008).

In this study we assumed that the association between acculturation mainstream antecedent conditions and wellbeing through a latent mediating variable, namely integration, would be invariant for Black and White group members in a mine in the North-West Province. Our hypothesis was confirmed, as we found an acceptable fit between the empirical data and the conceptual model. The fit between the 
data and the conceptual model indicates that the relations between antecedent conditions and well-being at work, through integration, were the same for Black miners and White miners. Thus, more multicultural norms, mainstream tolerance coupled with ethnic integration demands at home and at work resulted in a more subjective experience of success at work. This result confirmed the positive relations found in previous studies (Berry et al., 2006; Biela, 2008; Molokoane, 2007; Nchabeleng, 2008) between multicultural norms and practices, mainstream tolerance, integration demands and work success. It also confirmed the importance of taking both the mainstream and ethnic conditions into consideration in acculturation studies, as recommended by the proponents of the Integrated Acculturation Model (Bourhis et al., 1997). It, therefore, seems likely that a workplace culture that promotes the ethnic cultural maintenance of people, from diverse backgrounds, coupled with encouragement to participate in the mixed culture of South Africa, both at home and at work, would contribute to the experience of higher levels of subjective work success.

We were also interested in the mediating effect of this integration, in the path from positive antecedent variables to well-being, as measured by ill-health symptoms and subjective experience of work success. Our findings suggest an indirect and significant influence of positive conditions on subjective experience of work success. It could, therefore, be concluded that integration mediates the path from mainstream acculturation conditions to work success (sociocultural outcomes), but that it is unrelated to ill-health (psychological outcomes). It is remarkable that positive acculturation conditions and orientations were unrelated to ill-health. It could be speculated that positive conditions in the workplace, with regard to diversity, are probably more related to positive health outcomes (for instance, job satisfaction or life satisfaction) than to negative outcomes (such as ill-health). Positive and negative symptoms seem to have nomological networks that only show partial overlap. Our findings also seem to confirm Ward's et al. (2001) reasoning that psychological and sociocultural acculturation outcomes may have their own antecedents, because multiculturalism and mainstream tolerance coupled with coethnic integration demands were very strongly related to the subjective experiences of work success, whilst they were not related to physical and psychological ill-health symptoms. It can be concluded that integration demands fully mediate the path from mainstream positive conditions to sociocultural adjustment, and that multiculturalism matters for the experience of subjective work success.

Another aim of the study was to determine whether or not Black miners and White miners experience the mainstream antecedent conditions, intervening variables, and wellbeing at work differently. The results indicated that only multicultural norms were experienced differently by Black miners and White miners. Black miners experience higher levels of multicultural norms at work compared to White miners. This means that Black miners adhere more to multicultural norms in their environment than White miners. This result is in line with previous national surveys (HSRC, 2004, 2006) which indicated that Black miners are, in general, more optimistic than White miners about the new South Africa. Yet, we would like to emphasise that the effects are relatively small and, given that the means observed were well above scale midpoint, our findings suggest that multiculturalism is relatively well supported in both groups in the workplace. Analyses of group differences on item-level, for the various scales, also seem to suggest that most items were strongly endorsed, with little difference in the endorsement of the items in the two groups. The only exception, where medium effect sizes were observed between the two groups, was for the item on expectations from 'members of your cultural group want you to be a good member of your cultural group' as well as for South African society at large, where White miners scored lower than Black miners. However, it should be noted that support for multiculturalism should not be regarded as a given. Our results seem to differ from those obtained in previous European studies, as far as support for multiculturalism is concerned. More specifically, research in the Netherlands suggests that the level of support for multiculturalism varies significantly between the public and private domains, that cultural pluralism is not perceived as an important asset of society, and that mainstream society is not inclined to put much effort into minority integration. Verkuyten and Thijs (2002) found that the majority of members of Dutch society often emphasise the desirability of assimilation of ethnic minorities to the dominant culture. However, minorities will accentuate their own identity and the necessity of cultural maintenance, and they will expect more tolerance and participation from the mainstream culture (Arends-Tóth \& Van de Vijver, 2000). The Dutch mainstream are less supportive of multiculturalism than Dutch immigrants, presumably because mainstreamers will gain less from support of a plural society than immigrants. However, our findings suggest a different pattern of support in South Africa. Members of both ethnic groups have the same perception of reality, they evaluate the cost and benefits of multiculturalism in the same fashion, and the attitudes amongst the employees are conducive for establishing and maintaining good intergroup relations in the workplace. The means, of the Black miners and White miners, were quite similar on almost all instruments. Future studies should examine whether or not the support for diversification in the workplace, which is found in this study, is also found in other sectors.

The findings of the study contribute to the growing literature on acculturation in South Africa, in relation to how South Africans cope with the new evolving national identity, namely the Rainbow Nation. However, this study extends national surveys, that look at race perceptions of changes in the new South Africa, as it combines the influence of both mainstream and ethnic perceptions in predictions of wellbeing in the workplace of the New South Africa. Contrary to public perception and discourse, the results indicated that mainstream conditions impact in the same way on well- 
being at work for both Black miners and White miners. The results also indicate that both of these groups do not differ much in their experiences of these acculturation conditions and outcomes in this sample. The biggest limitation of study relates to the sample size, sample specificity, the choice of negatively phrased items as well as the design used. Future studies could consider other industries with larger sample sizes as well as longitudinal design to firmly establish cause and effect, as well as the impact of the issues covered in this study. In the light of recent xenophobic attacks on foreigners, future research could consider the experience of Indians and also various immigrant groups.

\section{Acknowledgement Competing interests}

The authors declare that they have no financial or personal relationship(s) which may have inappropriately influenced them in writing this paper.

\section{Authors' contributions}

L.T.B.J. (North-West University) was responsible for the literature review, the statistical analysis, and review and submission of the manuscript. F.J.R.V.D.V. (Tilburg University \& North-West University) attended to the review of the manuscript, advice on matters relating to the literature, statistical analyses, and final manuscript. S.A. (North-West University) was responsible for the data collection, initial literature review and manuscript preparation.

\section{References}

Ait Ouarasse, O. (2004). What immigration does to young people: The psychological acculturation of Moroccans in the Netherlands. Unpublished doctoral thesis, University of Tilburg, Tilburg, Netherlands.

Ait Ouarasse, O., \& Van de Vijver, F.J.R. (2004). Structure and function of the perceived acculturation context of young Moroccans in the Netherlands. International Journal of Psychology, 39, 190-204. http://dx.doi.org/10.1080/00207590344000367

Arbuckle, J.L. (2010). Amos 18. Chicago, IL: Smallwaters.

Arends-Tóth, J.V., \& Van de Vijver, F.J.R. (2006). Issues in conceptualization and assessment of acculturation. In M.H. Bornstein \& L.R. Cote (Eds.), Acculturation and parent-child relationships: Measurement and development, (pp. 33-62). Mahwah, NJ: Erlbaum.

Baron, R.M., \& Kenny, D.A. (1986). The moderator-mediator variable distinction in social psychological research: Conceptual, strategic, and statistical considerations. Journal of Personality \& Social Psychology, 51, 1173-1182. http://dx.doi. org/10.1037/0022-3514.51.6.1173

Barry, B. (2001). Culture and equality. Cambridge, United Kingdom: Polity Press.

Bekker, S., \& Leildé, A. (2004). Is multiculturalism a workable policy in South Africa? International Journal on Multicultural Societies, 5, 119-134.

Berry, J.W. (1970). Marginality, stress and ethnic identification in an acculturated Aboriginal community. Journal of Cross-Cultural Psychology, 1, 239-252. http:// dx.doi.org/10.1177/135910457000100303

Berry, J.W. (1980). Social and cultural change. In H.C. Triandis \& R.W. Brislin (Eds.), Handbook of cross-cultural psychology: Social psychology (vol. 5, pp. 211-279). Boston: Allyn and Bacon.

Berry, J.W. (2003). Conceptual approaches to acculturation. In K.M. Chun, P.B. Organista \& G. Marín (Eds.), Acculturation: Advances in theory, measurement and applied research (pp. 17-37). Washington, DC: American Psychological Association. http://dx.doi.org/10.1037/10472-004

Berry, J.W., \& Kalin, R. (1995). Multicultural and ethnic attitudes in Canada: An overview of the 1991 national survey. Canadian Journal of Behavioural Science, 27, 301-320. http://dx.doi.org/10.1037/0008-400X.27.3.301

Berry, J.W., Phinney, J.S., Sam, D.L., \& Vedder, P. (Eds.). (2006). Immigrant youth in cultural transition: Acculturation, identity and adaptation across national contexts. Mahwah, NJ: Erlbaum.

Biela, R. (2008). Multiculturalism in the work context of the South African Police Service. Unpublished doctoral dissertation, North-West University, Potchefstroom, South Africa.
Bissoondath, N. (1994). Selling illusions: The cult of multiculturalism in Canada. Toronto, Canada: Penguin.

Born, D.O. (1970). Psychological adaptation and development under acculturative stress. Social Science and Medicine, 3, 529-547. http://dx.doi.org/10.1016/00377856(70)90025-9

Bourhis, R.Y., Moïse, L.C., Perreault, S., \& Senécal, S. (1997). Toward an interactive acculturation model: A social psychological approach. International Journal of Psychology, 32, 369-386. http://dx.doi.org/10.1080/002075997400629

Breugelmans, S.M., \& Van de Vijver, F.J.R. (2004) Antecedents and Components of Majority Attitudes toward Multiculturalism in the Netherlands. Applied Psychology: An International Review, 53, 400-422. http://dx.doi.org/10.1111/ j.1464-0597.2004.00177.x

Brewer, M.B. (1997). The social psychology of intergroup relations: Can research inform practice. Journal of Social Issues, 53, 197-211. http://dx.doi. org/10.1111/j.1540-4560.1997.tb02440.x

Burns, N., \& Grove, S.K. (1993). The practice of nursing research, conduct, critique, and utilisation. (2nd edn.). Oxford: W.B. Saunders.

Clark, L.A., \& Watson, D. (1995). Constructing validity: Basic issues in objective scale development. Psychological Assessment, 7, 309-319. http://dx.doi. org/10.1037/1040-3590.7.3.309

Cohen, J. (1988). Statistical power analysis for the behavioural sciences. (2nd edn.). Orlando, FL: Academic Press.

Department of Labour. (2010). Commission for Employment Equity Annual Report 2009/2010. Pretoria: Government Printers.

Employment Equity Act 55 (1998). Pretoria, South Africa: Government Printers.

Hofmeyr, J.H. (2006, November). Report of the Sixth Round of the SA Reconciliation Barometer Survey. Wynberg: Institute for Justice and Reconciliation.

Holmbeck, G.N. (1997). Toward terminological, conceptual, and statistical clarity in the study of mediators and moderators: Examples from the child-clinical and the study of mediators and moderators: Examples from the child-clinical and pediatric psychology literatures. Journal of Consulting \& Clin
599-610. http://dx.doi.org/10.1037/0022-006X.65.4.599

Hoyle, R.H., \& Kenny, D.A. (1999). Sample size, reliability, and tests of statistical mediation. In R. Hoyle (Ed.), Statistical strategies for small sample research, (pp. 195-222). Thousand Oaks, CA: Sage.

HSRC. (2004). Social Cohesion and Social Justice in South Africa. An unpublished report prepared for the Presidency: Pretoria.

HSRC. (2006). Review of the impact of the Socio-Economic transformation on Social Cohesion in Communities across Society. An unpublished report prepared for the Presidency: Pretoria.

Jansen, J. (2011, June 02). When will we be enlightened: When more whites vote for ANC, more blacks for DA. The Times, p. 6 .

Jasinskaja-Lahti, I., Liebkind, K., Horenczyk, G., \& Schmitz, P. (2003). The interactive nature of acculturation: Perceived discrimination, acculturation attitudes and stress among young ethnic repatriates in Finland, Israel, and Germany. International Journal of Intercultural Relations, 27, 79-97. http://dx.doi. org/10.1016/S0147-1767(02)00061-5

Judd, C.M., \& Kenny, D.A. (1981). Process analysis: Estimating mediation in treatment evaluations. Evaluation Review, 5, 602-619. http://dx.doi. org/10.1177/0193841X8100500502

Khuzwayo, W. (2010, September 14). Shabangu blasts mines over 'minimal' reforms. Business Report. Retrieved September 16, 2010, from http://www.businessreport. co.za

Kline, R.B. (1998). Principles and practice of structural equation modeling. New York: Guilford.

MacKinnon, D.P., Lockwood, C.M., Hoffman, J.M., West, S.G., \& Sheets, V. (2002). A comparison of methods to test mediation and other intervening variable effects. Psychological Methods, 7, 83-104. http://dx.doi.org/10.1037/1082-989X.7.1.83

Makhalemele, O. (2005). Race and Identity in Schools: Young South Africans Engaging with a Changing Environment. Centre for the study of violence and reconciliation (CSVR). Retrieved April 11, 2011, from http://www.csvr.org.za/wits/papers/ paprctp7.htm

Molokoane, D.H. (2007). Predictors of acculturation outcomes amongst members of the South African Police in Gauteng. Unpublished master's thesis, North-West University, Potchefstroom, South Africa.

Nchabaleng, J. (2008). The acculturation process in the Head Office of the South African Police Services. Unpublished master's thesis, North-West University, Potchefstroom, South Africa.

Neto, F., Barros, J., \& Schmitz, P.G. (2005). Acculturation attitudes and adaptation among Portuguese immigrants in Germany: Integration or separation. Psychology \& Developing Societies, 17, 19-32. http://dx.doi. org/10.1177/097133360501700102

Pham, T.B., \& Harris, R.J. (2001). Acculturation strategies of Vietnamese Americans. International Journal of Intercultural Relations, 25, 279-300. http://dx.doi.org/10.1016/S0147-1767(01)00004-9

Preacher, K.J., \& Hayes, A.F. (2004). SPSS and SAS procedures for estimating indirect effects in simple mediation models. Behavior Research Methods, Instruments, \& Computers, 36, 717-731. http://dx.doi.org/0.3758/BF03206553

Richeson, J.A., \& Nussbaum, R.J. (2004). The impact of multiculturalism versus colorblindness on racial bias. Journal of Experimental Social Psychology, 40, 417-423. http://dx.doi.org/10.1016/j.jesp.2003.09.002

Sam, D.L. (2000). Psychological adaptation of adolescents with immigrant backgrounds. Journal of Social Psychology, 140, 5-25. http://dx.doi.org/10.108 $0 / 00224540009600442$

Schlesinger, A.M., Jr. (1992). The disuniting of America. New York, NY: Norton. 
Spector, P.E., \& Jex, S.M. (1998). Development of four self-report measures of job stressors and strain: Interpersonal conflict and work scale, quantitative workload inventory. Journal of Occupational Health Psychology, 3, 356-367. http://dx.doi. inventory. Journal of Occupational
org/10.1037/1076-8998.3.4.356

SPSS Inc. (2010). SPSS 18.0 for Windows. Chicago, IL: SPSS Inc.

Steyn, H.S. (1999). Praktiese beduidendheid: Die gebruik van effekgroottes. Wetenskaplike bydraes, Reeks B: Natuurwetenskappe Nr. 117. Potchefstroom, South Africa: PU vir CHE.

Swart, R.P.J. (2008). The acculturation of employees in a financial institution Unpublished master's dissertation, North-West University, Potchefstroom, South Africa.

Tabachnick, B.G., \& Fidell, L.S. (2007). Using multivariate statistics. (5th edn.). Boston, MA: Allyn \& Bacon.

Van Hemert, D.A., Van de Vijver, F.J.R., Poortinga, Y.H., \& Georgas, J. (2002). Structura and functional equivalence of the Eysenck Personality Questionnaire within and between countries. Personality and Individual Differences, 33, 1229-1249. http:// between countries. Personality and Individual
dx.doi.org/10.1016/S0191-8869(02)00007-7

Verkuyten, M., \& Thijs, J. (2002). Multiculturalism among minority and majority adolescents in the Netherlands. International Journal of Intercultural Relations, 26, 91-108. http://dx.doi.org/10.1016/S0147-1767(01)00039-6
Ward C., \& Rana-Deuba, A. (1999). Acculturation and adaptation revisited. Journal of Cross-Cultural Psychology, 30, 372-392. http://dx.doi. org/10.1177/0022022199030004003

Ward, C., \& Kennedy, A. (1999). The measurement of sociocultural adaptation International Journal of Intercultural Relations, 23, 659-677. http://dx.doi. org/10.1016/S0147-1767(99)00014-0

Ward, C., Bochner, S., \& Furnham, A. (2001). The psychology of culture shock. London: Routledge.

Wolsko, C., Park, B., Judd, C.M., \& Wittenbrink, B. (2000). Framing interethnic ideology: Effects of multicultural and color-blind perspectives on judgments of groups and individuals. Journal of Personality and Social Psychology, 78, 635-654. groups and individuals. Journal of Personality and
http://dx.doi.org/10.1037/0022-3514.78.4.635

World Health Organization. (1988). World Health Organization Cross-National Survey of Psychological and Somatic Symptoms. Geneva, Switzerland.

Zagefka, H., \& Brown, R. (2002). The relationship between acculturation strategies, relative fit and intergroup relations: Immigration-majority relations in Germany European Journal of Social Psychology, 32, 171-188. http://dx.doi.org/10.1002/ ejsp.73 